\title{
Evolving Role of PET in
}

Assessing the Efficacy of

Immunotherapy and Radiation

Therapy in Malignant Disorders

Editors

CHARLES B. SIMONE II

NICOLAS AIDE

ABASS ALAVI

\section{PET CLINICS}

www.pet.theclinics.com

Consulting Editor

ABASS ALAVI

January 2020 • Volume 15 - Number 1 